Supporting Information for

\title{
Exceptionally active and stable spinel nickel manganese oxide electrocatalysts for urea oxidation reaction
}

\author{
SivakumarPeriyasamy $\varpi^{\mathrm{a}}$, Palaniappan Subramanian $\#^{\mathrm{b}}$, Elena Levi ${ }^{\mathrm{a}}$, DoronAurbach ${ }^{\mathrm{a}}$, \\ AharonGedanken $^{\mathrm{a} *}$, Alex Schechter ${ }^{\mathrm{b}, *}$ \\ ${ }^{a}$ Department of Chemistry, Bar-Ilan Institute of Nanotechnology and Advanced Materials \\ (BINA), Bar-Ilan University, Ramat-Gan 52900, Israel \\ ${ }^{b}$ Department of Biological Chemistry, Ariel University, Ariel 40700, Israel
}




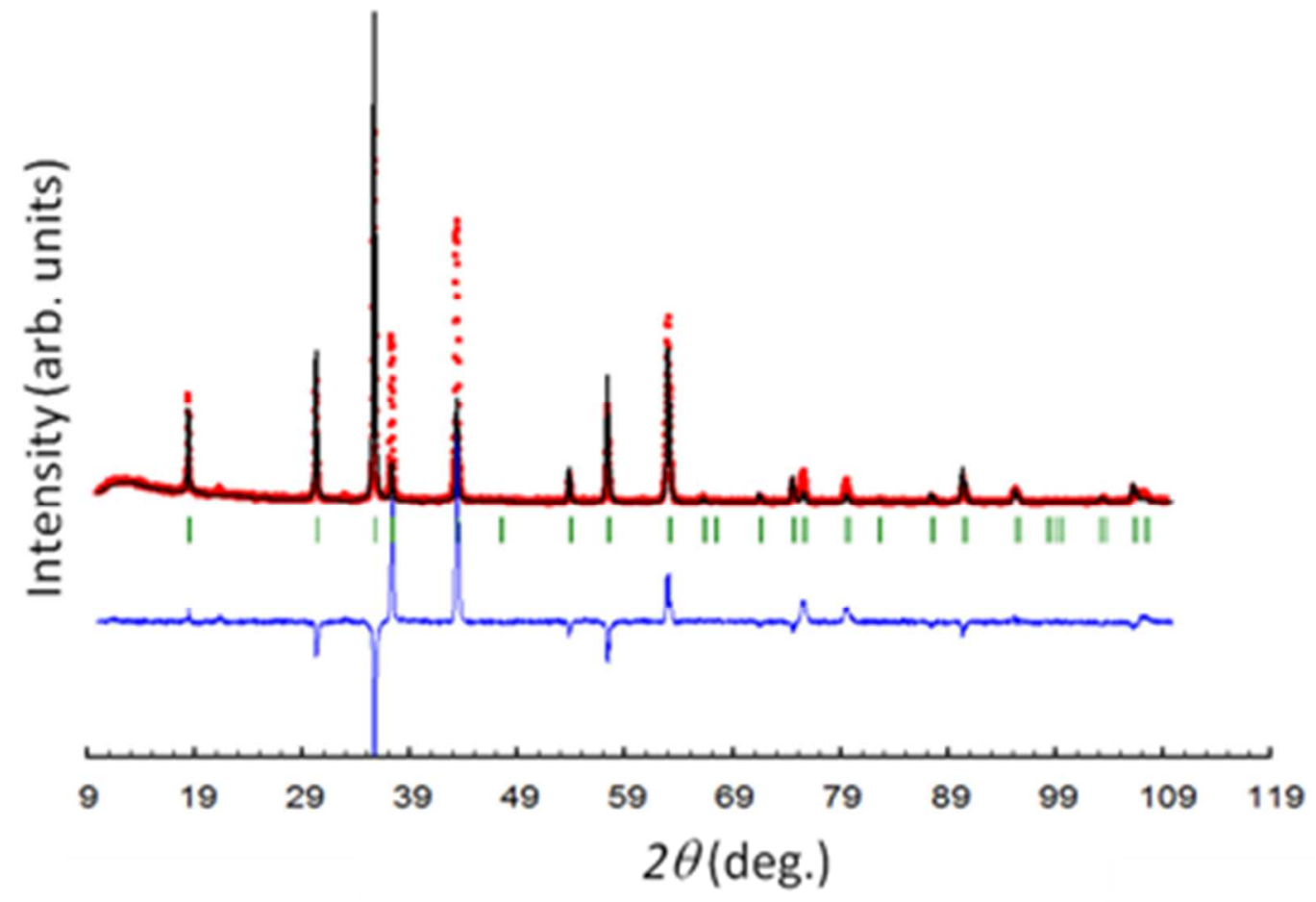

Fig. S1. Rietveld plot for composition $\mathrm{MnNi}_{2} \mathrm{O}_{4}$ obtained with one phase model: spinel (Mn) tet $(\mathrm{Ni})_{2}$ oct $\mathrm{O}_{4} \cdot \mathrm{R}_{\mathrm{b}}=41.86 \%, \chi^{2}=92.8$. 


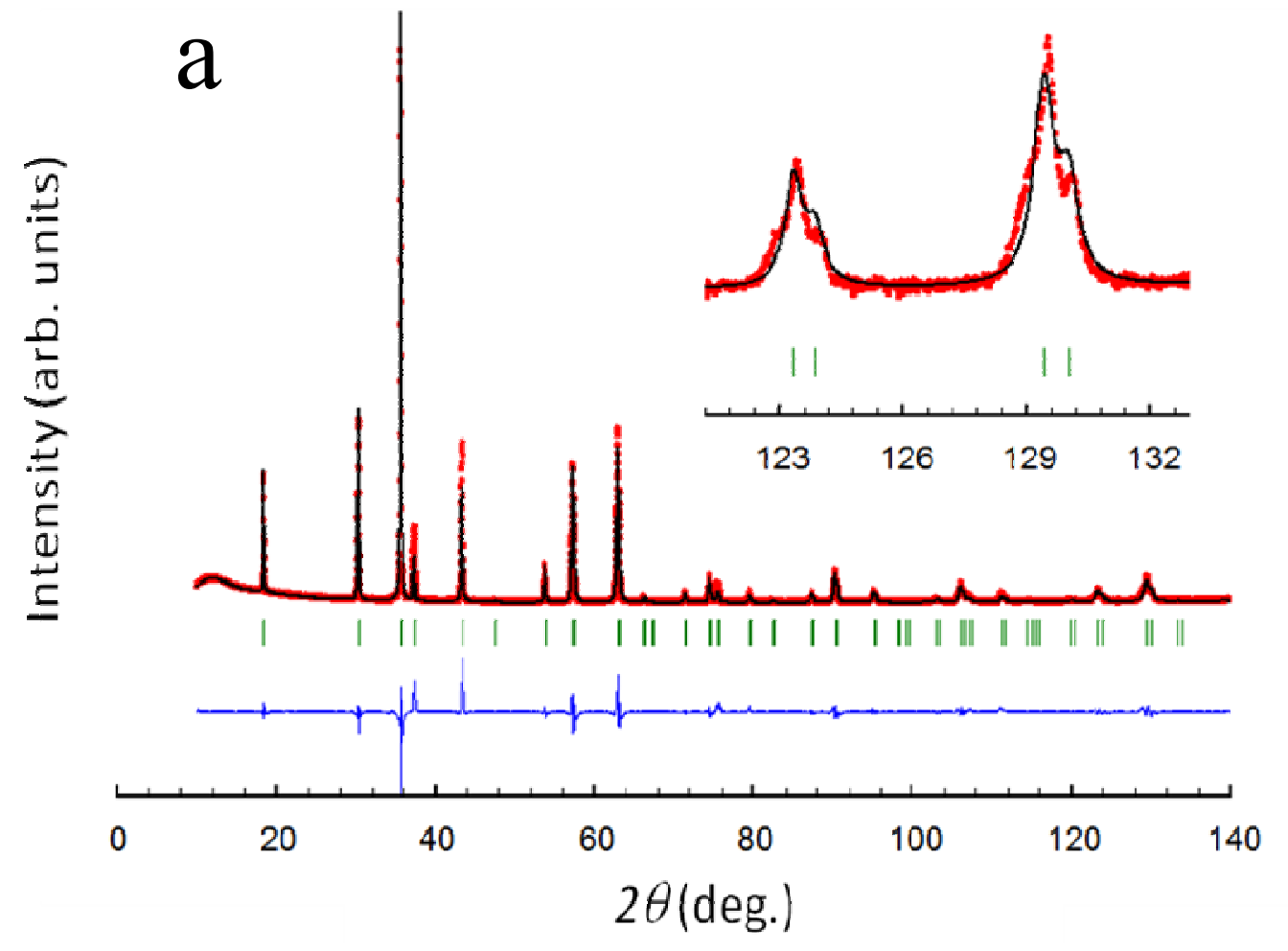




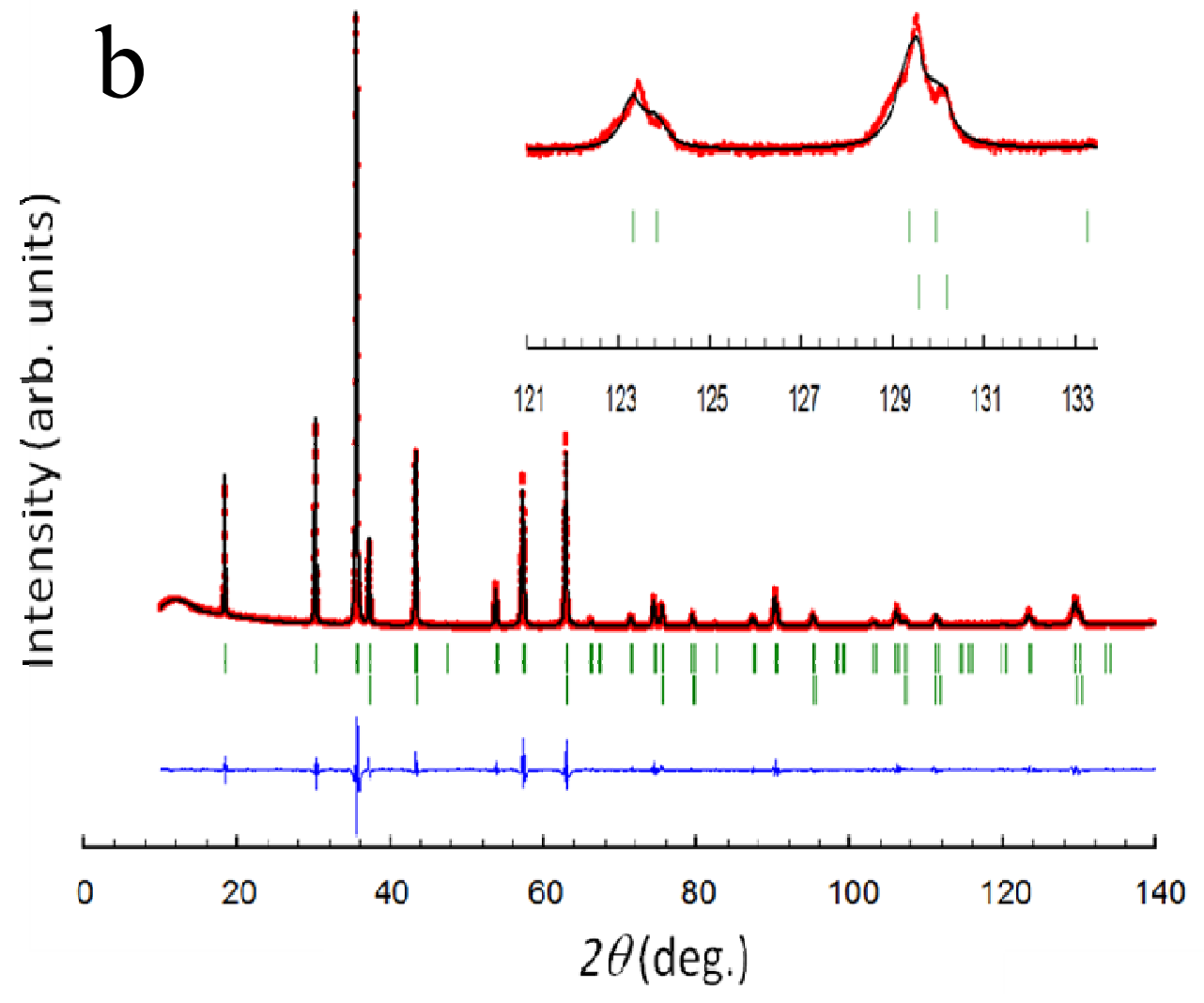




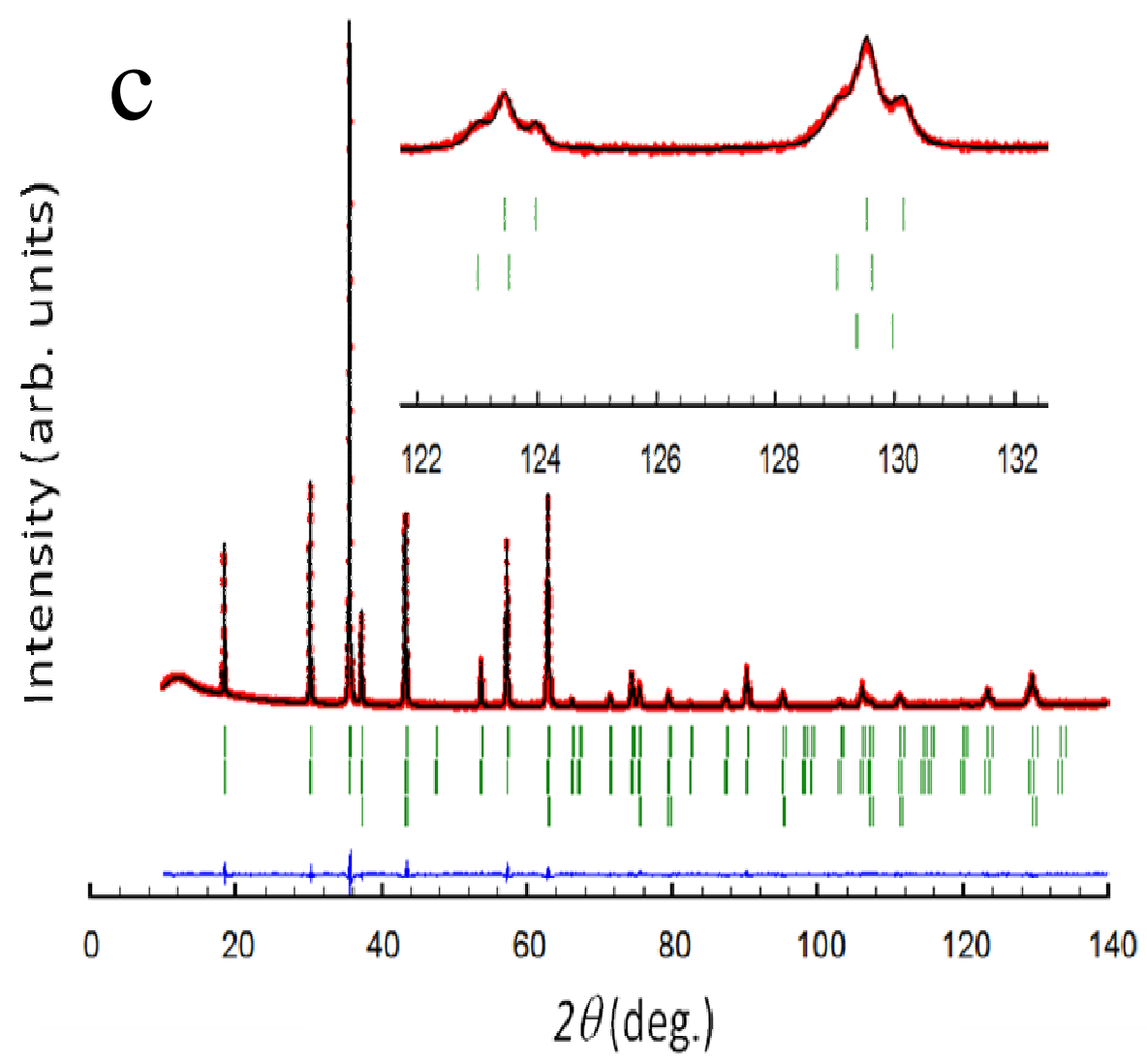

Fig. S2. Rietveld plot for composition $\mathrm{Mn}_{1.5} \mathrm{Ni}_{1.5} \mathrm{O}_{4}$ obtained with: a - one phase model - spinel $(\mathrm{Mn})_{\text {tet }}(\mathrm{Ni}, \mathrm{Mn})_{2}$ oct $\mathrm{O}_{4} . \mathrm{R}_{\mathrm{b}}=11.37 \%, \chi^{2}=49.7$. The insert shows that the calculated peak profiles do not fit well with the experimental ones; b - two phase model - spinel $(\mathrm{Mn})_{\text {tet }}(\mathrm{Ni}, \mathrm{Mn})_{2}$ oct $\mathrm{O}_{4}$ and $\mathrm{NiO} . \mathrm{R}_{\mathrm{b}}=16.14$ and $4.54 \%$, respectively, $\chi^{2}=24.13$. The insert shows that the calculated peaks are still clearly different from the experimental ones; $\mathrm{c}$ - three phase model - two spinels $(\mathrm{Mn})_{\text {tet }}(\mathrm{Ni}, \mathrm{Mn})_{2}$ oct $\mathrm{O}_{4}$ and $(\mathrm{Mn})_{\text {tet }}(\mathrm{Ni})_{2}$ oct $\mathrm{O}_{4}$, and $\mathrm{NiO} . \mathrm{R}_{\mathrm{b}}=2.63,2.78$ and $2.65 \%$, respectively, $\chi^{2}=5.32$. The insert shows that the calculated peaks fit well with the experimental ones.

Note: The calculated patterns are shown by solid curves; red dots show the observed intensities. The differences between the observed and calculated intensities are presented by blue curves. The short vertical bars indicate the position of Bragg reflections for the respective phases in the list. 